\author{
Brújula. Semilleros de Investigación \\ Volumen 8, Número 15, enero-junio, 2020. pp. 31-45 \\ Bogotá D. C., Colombia \\ ISSN 2346-0628 (en línea) \\ https://doi.org/10.21830/23460628.44
}

Política y Estrategia

\title{
Contención militar de la protesta social en Colombia
}

\author{
Eder Julián Barbosa Parra \\ Escuela de Armas Combinadas del Ejército
}

\section{RESUMEN}

El objetivo de este artículo es realizar una revisión documental sobre la protesta social, con especial énfasis en la participación que tiene el Ejército Nacional de Colombia en reprimirla o contenerla mediante la figura de asistencia militar a la Policía Nacional. Con este fin se siguió una metodología de tipo cualitativo con enfoque descriptivo, basada en una revisión documental de fuentes secundarias a través de buscadores especializados en la web. La información recogida se analizó desde un enfoque hermenéutico para tener una comprensión holística del tema en estudio. Como resultados concluyentes relevantes se destaca el fenómeno de policiamiento delas Fuerzas Militares en la contención de la protesta social, lo cual contraría su deber constitucional. Se resalta también la falta de un marco normativo nacional e internacional sobre el uso de armas menos letales (AML) en el control de la protesta social por parte de los agentes encargados. Finalmente, se encuentra con preocupación que mediante la figura de asistencia militar a la Policía Nacional el Ejército participa especialmente en contener movilizaciones que tienen lugar en entornos rurales y son realizadas por campesinos, indígenas y afrodescendientes que se expresan en contra de actividades de explotación minera y de extracción de petróleo.

\section{PALABRAS CLAVE}

Armas menos letales; contención; derecho; militar; policiamiento; protesta social.

\section{CITACIÓN}

Barbosa Parra, E. J. (2020). Contención militar de la protesta social en Colombia. Brújula, Semilleros de Investigación, 8 (15), 31-45. https://doi.org/10.21830/23460628.44 


\section{Introducción}

En Colombia, durante los últimos años se han registrado numerosas protestas sociales a lo largo y ancho del país, en las cuales grupos de estudiantes, trabajadores, campesinos y otros sectores han recurrido a este medio para expresarse en contra de las políticas del gobierno de turno para reclamar sus derechos. Este aumento de la acción de protesta ha ido de la mano con el incremento de los actos de represión, lo cual da lugar a un ambiente inadecuado para que los ciudadanos ejerzan este derecho debido a las estrategias coyunturales del gobierno. A esto se suma una serie de factores estructurales, como la continuación de grupos armados ilegales, el desarrollo de políticas y doctrinas contrainsurgentes por parte del Estado (las cuales han sido heredadas desde la Guerra Fría), su marco legal y la aplicación del modelo de contención por parte de las autoridades frente a la protesta, en donde se abre espacio para el uso intensivo de la fuerza y, con ella, la asistencia por parte de las Fuerzas Militares (FF. MM.).

En este contexto, se han documentado casos de abuso de fuerza por parte de las autoridades encargadas del control de la protesta social, represión y criminalización de quienes la ejercen. Preocupa especialmente la participación de las FF. MM. en el control de la protesta social, especialmente por el porte y uso de armas letales, ya que el riesgo que implica su uso hace que la represión del derecho social sea mayor. Asimismo, no hay un debate público sobre la protesta (Cruz, 2015), situación que se puede considerar anómala, pero que se explica por el histórico manejo represivo que se le ha dado, razón por la cual no se ha establecido como un problema social relevante porque ya tiene un carácter de normalidad.

En este contexto, este trabajo estudia la protesta social, prestando especial atención al con- trol que hace el Ejército Nacional de Colombia con la figura de asistencia militar a la Policía Nacional. Además, se documentan casos que se han presentado en el territorio y se analiza la necesidad de usar armas menos letales en este tipo de situaciones.

\section{La protesta social}

Para abordar la definición del término protesta social se requiere, de acuerdo con Casilimas (2017), comprender los conceptos de acción colectiva y movimiento social. Por un lado, la acción colectiva es entendida como el actuar organizado de un grupo de individuos en torno al mismo objetivo, en donde se coordinan factores cognoscitivos, afectivos y relacionales por medio de los cuales su trabajo grupal adquiere mayor sentido. Por otro lado, el movimiento social se define como "una acción colectiva que busca el cambio social” (p. 2). De acuerdo con Alain Touraine (2006), este segundo concepto se puede entender como "una conducta colectiva organizada de un actor luchando contra su adversario por la dirección social de la historicidad en una colectividad concreta” (p. 255).

Como se observa, diferentes autores se han preocupado por definir la protesta social, que se diferencia claramente del término movimiento social, por cuanto la característica esencial de la protesta social es que tiene un carácter coyuntural con cierto nivel de espontaneidad (Godás, 2007), en donde se aúnan esfuerzos públicos de manera sostenida para trasladar a las autoridades las reivindicaciones colectivas (Tilly \& Wood, 2010).

Ahora bien, en el ámbito normativo se agrega un adjetivo al término es cuestión, pues se hace referencia a la protesta pacífica, entendida de la siguiente manera:

Protesta pacífica: es una expresión legítima de los derechos de reunión, manifestación pública y pací- 
fica, libertad de asociación, libre circulación, a la libre expresión, libertad de conciencia, a la oposición y a la participación. Toda personas tiene derecho a reunirse o manifestarse tanto en una dimensión estática (reunión) como dinámica (movilización) de forma individual o colectiva y sin discriminación alguna; realizada con el fin de exigir, expresar, opinar, proponer en asuntos de interés nacional, departamental, municipal, local, general y particular. Todo ello, sin una condición distinta a que sea pacífica y en marco de respeto de los derechos de quienes no participan en la protesta. La protesta pacífica puede ser espontánea o planificada y/o informada. (Ministerio del Interior, 2018, p. 8)

En esta definición se reconoce la protesta pacífica como un derecho que tiene por objetivo "exigir, expresar, opinar y/o proponer" sobre asuntos públicos. Puede decirse entonces que el derecho a la protesta es un instrumento usado para reclamar y defender otros derechos. Se caracteriza además porque se puede desarrollar de manera individual o colectiva, estática o dinámica, siempre de manera pacífica, sin que su ejercicio atente contra los derechos de los demás. Para el interés de este escrito, se aborda la protesta social desde su dimensión dinámica o de movilización, desarrollada de manera grupal.

Ahora bien, desde una perspectiva política, la protesta se puede considerar un recurso contencioso por medio del cual quienes la ejecutan se enfrentan al poder para influir o afectar las decisiones tomadas por quienes gobiernan. Se configura, entonces, como un reto frente al Estado, que en su defensa llega a emplear, en algunas ocasiones, métodos de represión en el marco del concepto de poder del Estado, para lo cual considera el empleo de la "fuerza calificada” (Passerin, 2001).

\section{Desarrollo de la protesta social}

Ahora bien, cabe cuestionar, ¿por qué las masas recurren a la protesta? Normalmente este recurso es empleado por ciudadanos o grupos de diferentes sectores sociales que han recurrido a otros medios para dar a conocer sus peticiones, necesidades, reclamos, etc., pero que no han obtenido respuesta alguna o han encontrado dificultades para acceder a las decisiones públicas, o también que han encontrado restricciones en los procesos de apropiación de la riqueza social (Casilimas, 2017). Con esto, más allá de configurarse como un recurso sociopolítico, la protesta social permite evidenciar las rupturas sociales, el clima político, el avance o retroceso de la democracia de un determinado régimen político y la capacidad del gobierno para resolver los problemas ciudadanos.

En Colombia, al igual que en otros países de Latinoamérica, los ciudadanos recurren a la protesta social como recurso para que sus peticiones sean escuchadas; no obstante, la reacción o comportamiento de los gobiernos frente a ella puede ser diferente. En este sentido, Porta (2011) menciona dos modos de interpretación de la protesta social: por un lado, como el ejercicio de un derecho ciudadano y, por otro, como una disrupción del orden público.

Ahora bien, la protesta social no siempre ha sido reconocida como una acción política de los ciudadanos que mereciera, por parte del Estado, atención y el desarrollo de medidas para solucionar las causas de base. De hecho, de acuerdo con Casilimas (2017), "fue necesario esperar varios años para que los derechos vinculados a la protesta fueran legitimados e institucionalizados” (p. 5). En este mismo sentido, Leal (2002) sostiene que anteriormente era vista como un asunto de orden público, razón por la cual debía ser enfrentada con contundencia para reducirla totalmente.

Desde la perspectiva del orden público, cuando la protesta social pasa los límites legales, es decir, cuando deja de ser pacífica, su 
desarrollo puede ir en contra de los elementos que componen el mismo orden público, definido en el Código de Policía de la siguiente manera:

[C]onjunto de condiciones de seguridad, tranquilidad, salubridad, moralidad, ornato, goce de ambiente sano y espacio público que permiten la prosperidad general y el goce efectivo de los Derechos Humanos y el aseguramiento de la convivencia. (Policía Nacional de Colombia, 2008)

Desde el análisis de esta definición, toda protesta social no pacífica que altera el orden público pone en riesgo el goce de los Derechos Humanos y la convivencia pacífica. Desde este punto de vista, la protesta social es asociada a la desviación del orden, a la revuelta, al desarrollo de conductas delictivas, etc., razón por la cual la institución vigilante del orden público tiende a aplicar con contundencia la represión para tratarla.

\section{Metodología}

Esta investigación sigue una metodología de tipo cualitativo con enfoque descriptivo, basada en una revisión documental de fuentes de información secundaria, tales como investigaciones académicas, artículos de revista, documentos e informes institucionales, así como marcos normativos sobre la materia.

La documentación se realizó a través de buscadores web especializados, tales como Scielo, Redalyc, Google Académico y Dialnet. Para analizar la información se empleó un enfoque hermenéutico, mediante el cual se busca comprender de manera holística cada uno de los factores del objetivo de investigación.

\section{Resultados}

\section{La protesta como derecho y su marco normativo}

La protesta social se configura como un derecho que se enlaza con los artículos 20 y 37 de la Constitución Política de Colombia, referentes a la reunión pacífica y a la libertad de expresión. No obstante, en el marco normativo la regulación de la protesta social tiene un carácter punitivo, debido a que la doctrina contrainsurgente ha ganado campo a lo largo de la historia del país para resguardar la centralidad estatal.

En efecto, en la Ley 1453 de 2011, también conocida como Ley de Seguridad Ciudadana, por medio de la cual se dispusieron diferentes reformas al Código Penal y al Código de Procedimiento Penal, se sostiene un manejo represivo de la protesta social, puesto que en ella se penalizan distintas manifestaciones de sus repertorios (entre ellos la ocupación y bloqueo de vías públicas), pero no se determina de manera clara cuáles son las conductas punibles. Al respecto, Cruz (2015) presenta un análisis de las diferentes conductas punibles establecidas en este marco normativo y sus elementos de discusión. En la tabla 1 se resume su aporte.

Como se observa en la tabla 1, la normativa carece de precisión en la definición y limitación de los factores que componen las actividades o actos punibles, lo cual deja un "amplio espacio de discrecionalidad a las autoridades de policía y a los operadores jurídicos” (Cruz, 2015, p. 58), lo que va en detrimento del ejercicio de la protesta social. Esto se configura en una política en la que predomina la seguridad del Estado por encima de la seguridad ciudadana.

En este marco de ideas, es importante resaltar la necesidad de proteger el derecho a la protesta dentro del modelo democrático, sustentado en los siguientes argumentos: primero, que al relacionarse con los derechos de reunión, asociación y expresión, se considera necesaria dentro de todo régimen político de orden democrático (Linz, 1993); segundo, garantiza la pluralidad como elemento clave de la democracia; tercero, la libertad de protesta permite a los ciudadanos 
Tabla 1. Actos punibles de la protesta social

\begin{tabular}{|c|c|c|c|}
\hline Artículo & Acto punible & Pena & Discusión \\
\hline Artículo 9 & $\begin{array}{l}\text { Usurpación fraudulenta de in- } \\
\text { muebles. }\end{array}$ & $\begin{array}{l}48 \text { a } 59 \\
\text { meses. }\end{array}$ & No se determina el carácter fraudulento. \\
\hline Artículo 10 & $\begin{array}{l}\text { Empleo o lanzamiento de sus- } \\
\text { tancias u objetos peligrosos en } \\
\text { algunos lugares públicos. }\end{array}$ & $\begin{array}{l}16 \text { a } 90 \\
\text { meses. }\end{array}$ & $\begin{array}{l}\text { No se define el término objeto peligroso, de } \\
\text { tal manera que queda a discreción de las au- } \\
\text { toridades. } \\
\text { No se establecen las condiciones para supo- } \\
\text { ner la persecución de fines terroristas, ajenos } \\
\text { al sentido de la protesta social. }\end{array}$ \\
\hline Artículo 15 & Perturbación de actos oficiales. & $\begin{array}{l}24 \text { a } 48 \\
\text { meses. }\end{array}$ & $\begin{array}{l}\text { Los “actos oficiales" están definidos de ma- } \\
\text { nera amplia y ello riñe con la protesta, de } \\
\text { manera que afecta el derecho a la libertad } \\
\text { de expresión. }\end{array}$ \\
\hline Artículo 44 & $\begin{array}{l}\text { Incitación, dirección, constreñi- } \\
\text { miento y proporción de medios } \\
\text { para la obstaculización tempo- } \\
\text { ral o permanente, selectiva o } \\
\text { general de vías o infraestructu- } \\
\text { ra de transporte. }\end{array}$ & $\begin{array}{l}24 \text { a } 48 \\
\text { meses. } \\
\text { Multa de } \\
13 \text { a } 75 \\
\text { smlmv. }\end{array}$ & $\begin{array}{l}\text { El bloqueo de vías es el recurso más usado } \\
\text { en la protesta social, por cuanto permite la } \\
\text { visibilización de sus actores. }\end{array}$ \\
\hline $\begin{array}{l}\text { Artículos } \\
60 \text { y } 61\end{array}$ & $\begin{array}{l}\text { Se declara procedente la deten- } \\
\text { ción preventiva. }\end{array}$ & 210 días. & $\begin{array}{l}\text { Cuando el mínimo de la pena prevista por la } \\
\text { ley exceda los cuatro años de prisión. }\end{array}$ \\
\hline
\end{tabular}

Fuente: Elaborado por el autor con base en Cruz (2015).

desarrollar su función de control y gestión del gobierno, de manera que evita su extralimitación en el ejercicio del poder público; cuarto, permite la visibilización de grupos minoritarios que reclaman sus derechos, y, quinto, la protesta social permite que tengan lugar espacios de debate público para aquellos ciudadanos que carecen de medios y recursos para hacer oír su voz (Gargarella, 2012).

\section{Manejo de la protesta social a través del uso de la fuerza y la violencia}

Para abordar el manejo de la protesta social a través del uso de la fuerza y la violencia, primero es necesario reconocer las concepciones que se tiene de estos dos términos e identificar los fundamentos de la Fuerza Pública y del Estado en el control de la protesta pública.

Respecto a la violencia, tomando los aportes de Arendt (1970), se concibe como el uso legal que el Estado hace de las armas que ha monopo- lizado, en tanto que la fuerza se relaciona con el uso de la capacidad física para asegurar que los demás obedezcan.

Ahora bien, el empleo de la fuerza en el trato de la protesta social por parte de las autoridades se sustenta en la aplicación de la Doctrina de Seguridad Nacional (DSN), la cual ha abierto el paso a procesos de militarización de la Fuerza Pública y de policiamiento de las Fuerzas Militares —en concreto, del Ejército Nacional- como recursos estatales para el control del orden público en la contención y represión de las alteraciones provocadas por la protesta social cuando esta pierde su carácter pacífico.

La DSN tiene como fundamento el uso de la fuerza y la violencia por parte del Estado dentro de un marco de acción integral de combate. Se relaciona además con una perspectiva fundamentalmente militarista que permite la intervención de las Fuerzas Armadas en el control del orden público interno. 
Una de las políticas más relevantes que ha guardado especial relación con la DSN es la Política de Seguridad Democrática del expresidente Álvaro Uribe (2002-2010) (también alimentada por los altos niveles de inseguridad ciudadana en materia de secuestros, extorsiones, asesinatos selectivos, atentados, así como los hechos del 11 de septiembre de 2001 en las Torres Gemelas), en la cual, con "la consigna de guerra total contra la subversión, se criminalizaron los movimientos sociales y el repertorio de acciones colectivas” (Casilimas, 2017, p. 53).

En la aplicación de la DSN, la respuesta oficial del Estado frente a la protesta social es usar procedimientos legales de represión, en los cuales el uso de la fuerza se justifica en la seguridad de la nación. En esta misma línea, la DSN enfrenta la protesta social a través de medios de disuasión operacional, por ejemplo con la presentación de armas como tanques, tanquetas y carros de guerra, con lo cual se busca intimidar a los protestantes para generar miedo y pánico (Casilimas, 2017).

En este marco de ideas, se habla de la participación militar en el control del orden civil. Al respecto, vale mencionar que

[e]l DNS promueve una estrategia de acercamiento de los militares a los estamentos civiles desde diferentes niveles para legitimar el control sobre la población [...] siguiendo los imperativos para el conflicto de baja intensidad, entre los cuales se incluye la mencionada unidad de esfuerzos. (Casilimas, 2017, p. 62)

Considerando la posibilidad de que la protesta social puede tornarse violenta, y que dicha violencia se constituye como una amenaza que requiere ser contenida por parte del Estado por cuanto afecta a las autoridades y a terceros titulares de derecho, el poder reacciona ante esta dinámica de fuerzas que le contrarían en el uso de la fuerza militar.

\section{Trato militar de la protesta social}

En la discusión sobre la represión de la protesta social, diferentes autores hacen referencia al abuso de la fuerza por parte de las autoridades, así como al empleo de armas no convencionales o no autorizadas. Respecto al tema de abuso de la fuerza, en varias investigaciones y registros de noticias se presentan numerosos casos de denuncia por golpizas, ataques, asesinatos, destrucción de propiedades, bombardeo de gas lacrimógeno e incluso tortura por parte del Escuadrón Móvil Antidisturbios (Esmad) de la Policía Nacional (Casilimas, 2017; Cobos, 2018; Cruz, 2015; Jiménez y Turizo, 2011; Lalinde, 2019; Moreno, 2014; Ortegón, 2016; Yarce, 2013).

Teniendo en cuenta que el desarrollo de este escrito se enfoca en la participación del Ejército Nacional en los actos de control y represión de la protesta social, en adelante se exponen varios aportes sobre la figura de asistencia militar, que dispone su acción de apoyo a la Policía Nacional, no sin antes reconocer el origen histórico del fenómeno denominado militarización de la seguridad ciudadana y policiamiento del Ejército.

El trato armado para controlar la protesta social tiene sus orígenes en la década de los años 50 del siglo XX, cuando la institución policial estuvo marcada por su militarización en términos de dependencia, organización y capacitación. No obstante, su papel en la conservación del orden público y la protección de los derechos de los ciudadanos se vio desbordado en la década de los 80 ante el preocupante escenario de violencia causado por el narcotráfico, el paramilitarismo y los grupos guerrilleros, dado que estos grupos se surtían de mayor capacidad bélica.

Con la promulgación de la Constitución Política de 1991 se definió el carácter civil del 
cuerpo policial y se estableció que su fin es "el mantenimiento de las condiciones necesarias para el ejercicio de los derechos y libertades públicas, y para asegurar que los habitantes de Colombia convivan en paz" (art. 218). Asimismo, se definió que la finalidad de las Fuerzas Militares es "la defensa de la soberanía, la independencia, la integridad del territorio nacional y el orden constitucional” (art. 217). De esta manera, se presenta una diferencia sustancial entre el papel de la Policía y de la Fuerza Militar, cuya misión tiene que ver con el mantenimiento de la seguridad del Estado, sus instituciones y la protección de la seguridad nacional.

Las diferencias entre el papel de la Policía y el de las Fuerzas Militares, entre ellas el Ejército Nacional, se reflejan no solo en su fin, sino también en su modo operativo y los insumos — en este sentido, las armas — que utilizan para ello. Se suma a esto la lógica de obediencia reflexiva y de actuación individual que se aplica en la Policía, frente a la doctrina de obediencia debida de las Fuerzas Militares, en la cual los soldados no cuentan con la misma autonomía en su actuar, sino que efectúan las órdenes de sus superiores a cabalidad de manera conjunta (Lalinde, 2019).

A pesar de las diferencias sustanciales entre Policía y Ejército que establecen la Carta Magna y sus doctrinas, desde finales del siglo XX se ha presentado un fenómeno denominado policiamiento del Ejército. A raíz del recrudecimiento del conflicto armado interno, "el Ejército ha asumido tareas que en principio se entienden como de Seguridad Ciudadana, campo de acción propio de la Policía Nacional” (Yarce, 2013, p. 282).

Sobre las tareas que ha asumido el Ejército Nacional y que constitucionalmente no corresponden con sus responsabilidades, se documenta: "El control de tránsito en zonas urbanas, la ubicación de puestos de control para la verificación de antecedentes, cubrimiento de eventos masivos, patrullaje en zonas residenciales, presencia permanente en las carreteras" (Yarce, 2013, p. 282).

En este sentido, el cubrimiento de eventos masivos abarca, entre otros, la protesta social. De hecho, de acuerdo con el Código de Policía, el cuerpo policial puede solicitar la ayuda del Ejército Nacional en el control de protestas sociales bajo la figura de asistencia militar.

Asimismo, desde 1954, con el Decreto 1695 se creó la Policía Militar como cuerpo especializado para controlar la protesta social. La capacidad bélica de este órgano comprende el porte de armas cortas (pistolas de $9 \mathrm{~mm}$ ) y armas largas (fusiles M-1 o Galil), lo que aumenta su capacidad de disuasión y, ambiguamente, la presunción de combate cuerpo a cuerpo (Casilimas, 2017). Además, se suma la disposición que tiene la Policía Militar de la Infantería de Marina. La participación de estos órganos se alinea con la doctrina Mansfield, por la cual se justifica la participación militar en caso de insuficiencia de la capacidad policial.

La presencia militar en el cubrimiento de funciones policiales genera varios efectos. Primero, confusión en la comunidad sobre las funciones que le compete a cada una de estas instituciones; segundo, la desnaturalización de los ámbitos por proteger o combatir (como por ejemplo, el orden público, la seguridad ciudadana, la convivencia, el ejercicio de derechos y libertades); tercero, un aumento en la percepción de inseguridad; y cuarto, una imagen del Estado como agente generador de miedo.

Sumado a tales efectos, valga mencionar que

esa desnaturalización de funciones acarrea una politización de las Fuerzas Militares, una difuminación de las fronteras entre lo civil y lo miliar, es decir, un 
rompimiento de lo que separa el conflicto armado de la mera delincuencia y una deslegitimación de la Fuerza Pública surgida por un corrompimiento de esta en razón de los probados vínculos de algunos de sus miembros con las organizaciones armadas, poniendo en riesgo lo que se supone intenta proteger: la seguridad ciudadana. (Yarce, 2013, p. 283)

\section{Casos de criminalización de la protesta con participación del Ejército}

La participación del Ejército Nacional en la contención de la protesta social es tema de debate principalmente por dos razones: en primer lugar, por los efectos de su presencia en este tipo de actos públicos y porque no se rige a la disposición constitucional respecto a su papel. En segundo lugar, porque el trato militar de la protesta da lugar a la violación del principio de proporcionalidad, que se refiere a la aplicación de la fuerza de acuerdo con la progresión de comportamiento de los ciudadanos según su grado de intensidad. Con este principio se busca una graduación de la fuerza entre los agentes de disuasión y de reacción, partiendo de la presencia ostensiva hasta el uso de arma de fuego (Policía Nacional de Colombia, 2008).

En este sentido, distintos autores reportan casos en los que el Ejército Nacional ha participado en la contención de la protesta social, lo cual ha dado lugar a la violación del principio de proporcionalidad y a que su actuar haya ido en contra de la protección de los ciudadanos y sus derechos.

Jiménez y Turizo (2011) hacen referencia a la presencia de unidades militares en las ciudades del territorio nacional y señalan que se han presentado choques entre el Ejército y la Policía —a lo cual se denomina "fuego amigo"-, así como confusión sobre la misión que corresponde a cada una de estas instituciones.

Por su parte, Cobos (2018) aborda el tratamiento militar de la protesta social que se ha aplicado en el pueblo indígena Nasa, más pre- cisamente sobre el Movimiento de Liberación de la Madre Tierra. En este trabajo se resalta el pronunciamiento del Alto Comisionado de las Naciones Unidas para los Derechos Humanos en Colombia sobre la necesidad de que las protestas civiles sean tratadas como tales, para lo cual se precisa eliminar la represión militar que hace el Ejército. En este mismo sentido, el autor resalta la manifestación de la Cruz Roja sobre el tema y la figura de asistencia militar que da paso al Ejército en el control de la protesta. Al respecto,

se recalca que el Ejército, al prestar asistencia a la Policía, no se encuentra sujeto al Derecho Internacional Humanitario sino al Derecho Internacional de los Derechos Humanos y a la legislación nacional que se aplica en estos casos de asistencia. Por lo tanto, el uso de la fuerza y las armas de fuego han de quedar reducidas a casos sumamente excepcionales, y en todo caso cumpliendo con los principios de proporcionalidad, legalidad, necesidad y precaución. (Cobos, 2018, p. 11)

En su trabajo sobre la protesta social, Lalinde (2019) referencia datos estadísticos del Instituto Nacional de Medicina Legal y Ciencias Forenses en materia de homicidio y violencia interpersonal (figuras 1 y 2).

Desafortunadamente, dichos datos no presentan una discriminación clara de los autores (Policía o Fuerzas Armadas) ni tampoco permiten diferenciar el contexto de los hechos, lo cual impide hacer una medición de los casos de violencia interpersonal $\mathrm{u}$ homicidios en contextos de protesta social.

En el trabajo de Lalinde (2019) se presenta el caso concreto del líder social Helivaneth Uribe, integrante de la Guardia Indígena del Catatumbo, quien junto con otros compañeros que participaron en el paro agrario de 2013 en el Catatumbo fueron víctimas de ultraje por parte de la Policía y el Ejército. Asimismo, en el informe presentado por Betancourt (2016) para el Observatorio de 


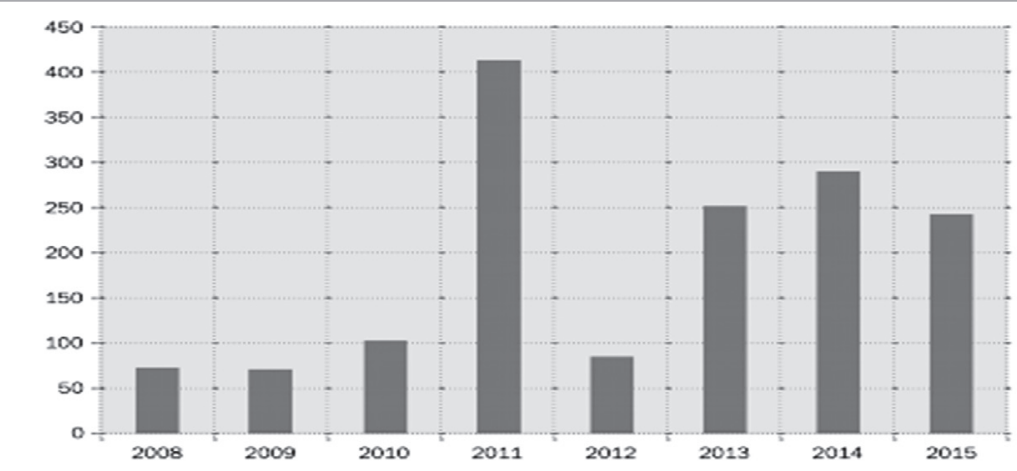

FUENTE: elaboración propia con base en datos del Instituto Nacional de Medicina Legal y Ciencias Forenses (2008, p. 34: 2009. p. 37: 2010, p. 31: 2011, p. 76; 2012, p. 128; 2013. p. 85: 2014, p. 101; 2015, p. 83).

Figura 1. Presuntos casos de homicidio por parte de la Fuerza Pública y las FF. MM. Fuente: Lalinde (2019, p. 129).

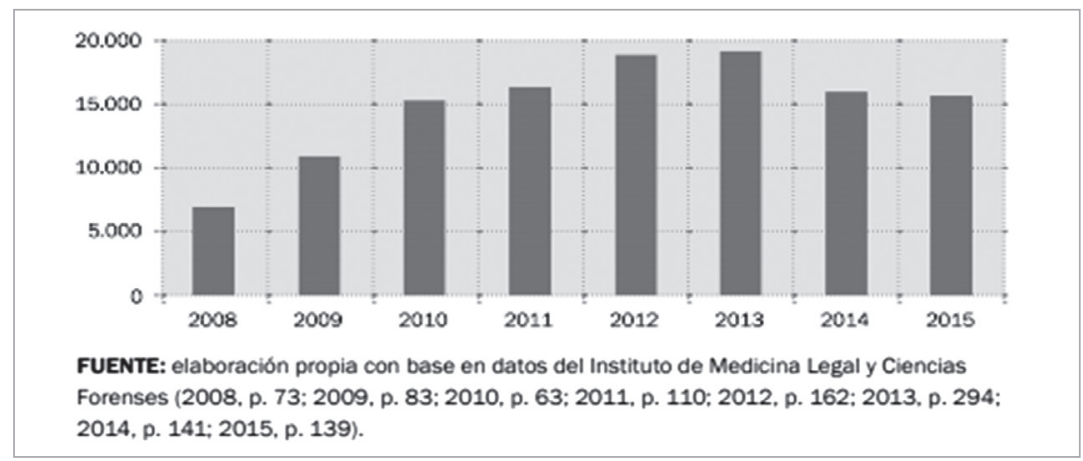

Figura 2. Presuntos casos de violencia interpersonal por la Fuerza Pública y las FF. MM. Fuente: Lalinde (2019, p. 129).

Conflictos Mineros de América Latina (OCMAL) y el Centro Nacional Salud, Ambiente y Trabajo (CENSAT) (2016), se abordan los distintos tipos de violencia y criminalización ejercidos contra las comunidades afectadas por proyectos mineros y activistas del medio ambiente que recurren a la protesta social como medio de visibilización y reclamo de sus derechos.

Al hacer una caracterización de la criminalización contra las comunidades, Betancourt (2016) menciona como agentes protagónicos al Estado y al sector público, señalando que "las entidades estatales coordinan acciones judicia- les, punitivas, administrativas, incluso extralegales, aunque con un manto de legalidad” (p. 22). Asimismo, como parte de la represión de la protesta pública por parte del Estado, menciona el asesinato de manifestantes durante marchas, tomas, bloqueos y otros actos colectivos de protesta y manifestación social en lugares públicos en contra de la actividad minera. Las medidas de represión son señaladas en el informe por la extralimitación del poder, así como por el uso excesivo de la fuerza.

Igualmente, sostiene que la participación de las Fuerzas Armadas en la contención de la 
protesta social de las comunidades que se expresan en contra de los proyectos mineros y a favor del medio ambiente sigue una doctrina militar de combate al enemigo y deja un mensaje de miedo en la población, "pues se aprovecha este momento, dentro de la institucionalidad legalista, para hacer un uso ejemplarizante de la fuerza del Estado y del poder de la minería” (Betancourt, 2016, p. 28). Aunado a la represión militar de la protesta social y la violencia que se ejerce sobre este derecho, se asocian hechos como asesinatos y detenciones arbitrarias (Betancourt, 2016).

Por su parte, Toro et al. (2017), en su trabajo sobre la lucha de comunidades campesinas, indígenas y afrodescendientes en contra de proyectos de explotación petrolera, documentan que "desde finales de los años sesenta, las diferentes expresiones regionales del régimen político dominante privilegiaron el tratamiento de la fuerza, de represión militar y de exclusión política a los conflictos sociales antes que las salidas democráticas y de construcción de consensos” (p. 76). De esta manera, la protesta social ha sido tratada desde la acción militar.

Uno de los últimos periodos de gobierno que ha presentado mayor auge de la protesta social en Colombia fue el primer mandato de Juan Manuel Santos (2010-2014). De acuerdo con Cruz (2015), "las movilizaciones y las formas de contención implementadas [...] permiten inferir un marcado aumento de la criminalización y la represión” (p. 49). Se documenta un total de 2.027 protestas o luchas sociales ${ }^{1}$. Varias de estas protestas o movilizaciones fueron de gran concurrencia y de amplio alcance territorial, entre ellas están: el paro nacional universitario de octubre y noviembre de 2011, el paro cafe-

1 El autor en mención abarca aquellas movilizaciones en las cuales se congregaron diez o más personas en un espacio público en el reclamo de sus reivindicaciones. tero de 2013, el paro nacional agrario de agosto y septiembre de 2013 y el paro del Catatumbo del 2013. Frente a estos actos, se documentan repuestas represivas y de criminalización por parte del Estado a través de la acción policial.

Uno de los casos de represión que más llama la atención fue el paro nacional agrario, sobre el cual se documenta que

902 personas fueron víctimas de algún tipo de agresión. Del total de los casos, 15 personas fueron asesinadas, 7 víctimas de algún tipo de acto cruel o tortura, entre ellos un abuso sexual; 315 personas detenidas arbitrariamente, 40 personas víctimas de fuertes golpizas, 329 que a causa de los ataques resultaron con algún tipo de lesión y/o herida y 5 personas con heridas graves que les derivó incapacidad parcial o total. (Movimiento Nacional de Víctimas de Crímenes de Estado [MOVICE] y Coordinación Colombia Europa Estados Unidos [CCEEU], 2013, p. 23)

Sobre estos hechos preocupa que "la Policía Nacional es responsable del 88,15 \% de los casos y el Ejército Nacional del 1,55 \%, en tanto que para el 8,54\% no se pudo establecer quiénes fueron los responsables” (MOVICE \& CCEEU, 2013, p. 23).

Es importante tener presente que la represión y criminalización de la protesta social no se presenta de manera uniforme, sino que varía según sus características, sus métodos de visibilización y la manera como estos surten efecto en las dinámicas del orden público. En este sentido, el tipo de protestas tratadas con mayor represión son aquellas en las que sus actores han optado por el bloqueo de vías principales.

\section{Uso de armas menos letales (AML) en el control de la protesta social}

Uno de los temas más controversiales sobre la asistencia militar que presta el Ejército Nacional a la Policía para controlar y contener marchas sociales tiene que ver con el uso de armas letales por parte de sus agentes, lo cual, como ya se ha expuesto, genera riesgos para la vida 
de los ciudadanos que ejercen su derecho a la protesta y se da lugar a la violación del derecho de proporcionalidad.

En este contexto, resulta necesario abordar el tema de uso de armas menos letales (AML) por parte de las instituciones encargadas de la contención y control de la protesta social, todo visto desde una perspectiva de su legalidad, viabilidad y conveniencia.

Las AML son definidas como "dispositivos diseñados para generar un efecto específico e intermedio que permita neutralizar o incapacitar temporalmente objetivos en situaciones de riesgo medio, reduciendo la probabilidad de una fatalidad” (Organización de las Naciones Unidas [ONU], 2016, p. 6).

El uso de este tipo de dispositivos por parte de las fuerzas del Estado tiene como propósito neutralizar un objetivo y reducir el riesgo de fatalidad, por cuanto sus efectos son más reversibles. No obstante, se reconoce que su empleo indebido puede provocar lesiones severas e incluso la muerte (Amnistía Internacional, s. f.). Su empleo tiene como finalidad controlar masas en contextos de protestas o manifestaciones, con lo cual se evitan los enfrentamientos uno contra uno.

En el ámbito internacional, el uso de AML por parte de los agentes de seguridad pública como la Policía — no es un asunto reciente, pues desde hace al menos un siglo diferentes países los han estado incorporando, especialmente para el control de masas, como es el caso de la protesta social.

Por su parte, en América Latina y el Caribe diferentes Estados han realizado modificaciones en sus marcos jurídicos para utilizar AML y han definido protocolos operativos. A pesar de que hay cierto avance normativo, distintas organizaciones han advertido en la región sobre el riesgo de emplear estos dispositivos y sobre la necesidad de que haya un mayor desarrollo normativo claro y preciso, de cara a los cientos de casos que se registran a través de acciones judiciales por el daño que causan.

Ahora bien, a continuación se presenta el marco normativo internacional que aborda este tema o que es vinculante:

- Principios básicos de las Naciones Unidas sobre el empleo de la fuerza y de armas de fuego por los funcionarios encargados de hacer cumplir la Ley. En el cual se establece que los gobiernos deben ampliar el espectro de métodos y armas y municiones de uso público institucional, incluyendo las AML, evitando medios letales o excesivamente lesivos.

- Convención de Naciones Unidas contra la Tortura.

- Convención sobre Ciertas Armas Convencionales.

- Código de conducta para funcionarios encargados de hacer cumplir la ley.

- Principio básico sobre el empleo de la fuerza y armas de fuego por funcionarios encargados de hacer cumplir la ley.

\footnotetext{
Valga resaltar que

todas las disposiciones normativas relativas al uso de la fuerza deben, necesariamente, observar de manera amplia los derechos humanos y establecer una secuencia o gradación de medios adecuados para reprimir actos violentos, dirigiendo la fuerza solo contra las personas que participan en tales actos en el grado mínimo necesario (respetando los principios de legalidad, necesidad y proporcionalidad) y preservando a aquellas ajenas al altercado, ya sean manifestantes pacíficos o transeúntes circunstanciales. (ONU, 2016, pp. 18-19)
}

Específicamente, en el caso colombiano, el uso de AML está reglamentado en función de las necesidades de servicio del cuerpo policial en el documento Criterios para el empleo de armas 
no letales (Policía Nacional de Colombia, 2009). En el caso concreto de control de disturbios, se considera la utilización de una amplia variedad de granadas de mano con agentes irritantes / lacrimógenos y de aturdimiento, de efecto múltiple y de proyección de perdigones.

Ante la debilidad normativa respecto al uso de AML, hace falta que se desarrollen instrumentos legales que den claridad sobre los siguientes factores: quiénes pueden y quiénes no pueden portar y usar AML; qué tipo de situaciones ameritan su uso; escala de efectos según el dispositivo y su uso, capacitación sobre su uso, regulación sobre su comercialización, consecuencias físicas y cognitivas derivadas del ataque con AML, y discusión desde la sociedad civil sobre el uso de AML por las fuerzas del orden (ONU, 2016).

La dificultad en el surgimiento de marcos normativos consolidados sobre el uso de AML se deriva de la poca literatura especializada sobre el tema, aunado a la falta de articulación desde las distintas ramas de investigación. Por un lado, desde la perspectiva médica se habla de las consecuencias físicas y cognitivas que se pueden derivar de la exposición a este tipo de armas. Por otro, desde la perspectiva de las políticas públicas se estudia el efecto de las AML en el desempeño policial o de los agentes de control, sus protocolos y el entrenamiento para su uso. Finalmente, las organizaciones sociales centran su atención en analizar los riesgos que trae el abuso de AML en contravía de los Derechos Humanos.

Para el caso de Colombia, el aporte normativo más importante es la clasificación de AML que se hace en el documento Criterios para el empleo de armas no letales, de la Dirección General de la Policía Nacional (2009). Dicha clasificación se presenta en la tabla 2.

Tabla 2. Clasificaciones seleccionadas de armas menos letales

\begin{tabular}{|c|c|c|c|}
\hline Tipo & Descripción & Ejemplos & Lesiones asociadas \\
\hline $\begin{array}{l}\text { Energía } \\
\text { cinética }\end{array}$ & $\begin{array}{l}\text { Procuran influir en el comportamiento } \\
\text { generando incomodidad física o dolor } \\
\text { mediante el impacto no punzante o } \\
\text { perforante de la munición. Continúan } \\
\text { siendo los dispositivos de uso más ex- } \\
\text { tendido debido a su simplicidad, bajo } \\
\text { costo y fácil adaptabilidad a distintas } \\
\text { plataformas de lanzamiento. }\end{array}$ & $\begin{array}{l}\text { Municiones: proyectiles de goma, } \\
\text { sacos rellenos, balas de plástico, } \\
\text { de plano aerodinámico, rellenas } \\
\text { de pintura, gel, CS, CN u OC, } \\
\text { entre otros. } \\
\text { Dispositivos de impacto: porras, } \\
\text { bastones policiales u otras armas } \\
\text { diseñadas para golpear. Existen } \\
\text { distintos dispositivos de lanza- } \\
\text { miento, como cañones de agua, } \\
\text { humo o aire. }\end{array}$ & $\begin{array}{l}\text { Pueden penetrar o lacerar la } \\
\text { piel, requerir extracción, le- } \\
\text { sionar los ojos, producir frac- } \\
\text { turas, conmoción cerebral, } \\
\text { lesiones en órganos internos, } \\
\text { hemorragias. Si el disparo fue } \\
\text { efectuado a corta distancia o } \\
\text { sobre el pecho, el abdomen o } \\
\text { la cabeza, estas lesiones pue- } \\
\text { den ser fatales. }\end{array}$ \\
\hline Eléctricas & $\begin{array}{l}\text { Utilizan una descarga eléctrica para } \\
\text { anular el sistema nervioso central y } \\
\text { provocar una contracción involuntaria } \\
\text { del tejido muscular. }\end{array}$ & $\begin{array}{l}\text { Taser, bastones paralizantes, pi- } \\
\text { canas, armas eléctricas inalámbri- } \\
\text { cas, escudos eléctricos. }\end{array}$ & $\begin{array}{l}\text { Pueden producir quemaduras } \\
\text { de distinto grado, paro res- } \\
\text { piratorio, asfixia, fibrilación, } \\
\text { tetanización muscular. }\end{array}$ \\
\hline $\begin{array}{l}\text { Energía } \\
\text { dirigida o } \\
\text { lumínica }\end{array}$ & $\begin{array}{l}\text { Utilizan rayos láser u otros haces de } \\
\text { energía lumínica para causar proble- } \\
\text { mas de visión y desorientación. En el } \\
\text { caso de las granadas de aturdimiento, } \\
\text { también se produce un fuerte sonido } \\
\text { cuando detonan. }\end{array}$ & $\begin{array}{l}\text { Dispositivos de rayos láser de } \\
\text { alta energía y granadas de } \\
\text { aturdimiento, entre otros. }\end{array}$ & $\begin{array}{l}\text { Respiración dificultosa, des- } \\
\text { orientación, náuseas, dolor, } \\
\text { vértigo. }\end{array}$ \\
\hline
\end{tabular}




\begin{tabular}{cl}
\hline Tipo & \multicolumn{1}{c}{ Descripción } \\
\hline Químicas & Utilizan las propiedades tóxicas de las \\
& sustancias químicas para incapacitar \\
& con carácter temporal. Dependiendo \\
& del tipo de agente químico que con- \\
& tengan, tendrán un efecto distinto: \\
& asfixiante, paralizante, lacrimógeno o \\
& irritante, entre otros.
\end{tabular}

Acústicas o Utilizan la tecnología de sonido audible sónicas para entregar mensajes de advertencia, tales como disturbios, grabaciones o tonos de aviso. Existen AML infrasónicas, sónicas y ultrasónicas, con alcance y efectos diferenciados.

\section{Ejemplos}

Utilizan sustancias químicas como gas pimienta, gas lacrimógeno, bombas de peste, materiales antitracción.

\section{Dispositivos que aturden a través} de una transmisión de sonido a cierto nivel de decibeles.

Lesiones asociadas

Los efectos en los ojos incluyen la inyección conjuntival, defectos epiteliales de la córnea, neovascularización corneal, conjuntivalización persistente, opacidades de la córnea y disminución de la agudeza visual.

Rotura de tímpano, pérdida de audición temporal o permanente, pérdida de equilibrio Según el tipo de onda: las infrasónicas producen incomodidad, perturbación de la función auditiva; las sónicas causan interferencia, dolor del tejido; las ultrasónicas generan efectos psicológicos difusos, dolor, hasta pérdida de tejido.

$\begin{array}{ll}\text { Bioquímicas } & \begin{array}{l}\text { Generalmente son utilizadas para la de- } \\ \text { tención de animales salvajes. Producen } \\ \text { de manera inmediata un agente analgé- } \\ \text { sico incapacitante. }\end{array}\end{array}$

Calmantes, convulsionantes, incapacitantes.

Intoxicación, laceraciones, descompensación orgánica. Actúan sobre el sistema nervioso central, generando conmoción, desorientación e incapacitación motriz.

Electromag- Utilizan la emisión de ondas electronéticas magnéticas y pueden tener efectos sobre los seres humanos o sobre las infraestructuras (inhabilitación de sistemas y redes de comunicaciones).

Neumáticas Utilizan como fuerza impulsadora del proyectil la originada por la expansión de un gas comprimido. Son denominadas también de aire comprimido o airsoft. Según su funcionamiento, se distinguen entre mecánicas, con motor eléctrico o aquellas que emplean $\mathrm{CO} 2$.

Combinadas Integran dos o más tipos de tecnologías al combinar energía cinética, lumínica, sónica, química, acústica, entre otras. En el campo de las AML, el desarrollo tecnológico es continuo, por lo que la aparición de nuevos dispositivos con tecnología combinada es una constante.
RF Jamming, inhibidoras de frecuencia de radio y celular.

Marcadoras que utilizan proyectiles de caucho, polvo inerte, gas pimienta, pintura, entre otros.
Quemaduras, pérdida de la visión y alteraciones mentales como pérdida de la memoria, desorientación yconfusión.

Dependiendo del tipo de proyectil que empleen, pueden ocasionar las lesiones asociadas de energía cinética o composición química

Lesiones varias en función de la tecnología empleada.

\begin{abstract}
Municiones traumatizantes, dispositivos químicos y cinéticos de dispersión, dispositivos químicos y ópticos de dispersión.
\end{abstract}




en Estados Unidos se documenta, entre 2001 y 2015, la muerte de 670 personas impactadas con pistolas Taser por parte de agentes de policía que las han empleado de forma inadecuada: en exposición prolongada o repetida, asfixia, uso de marca pasos o ingestión de sustancias tóxicas antes del impacto.

\section{Conclusiones}

La intervención del Ejército Nacional en el control de la protesta social a través de la figura de asistencia militar a la Policía Nacional da lugar al fenómeno denominado policiamiento de las Fuerzas Militares, en donde se yuxtapone el deber constitucional definido para estas instituciones, de manera que se genera confusión sobre su papel y se abre campo para situaciones de desproporcionalidad de la fuerza entre protestantes y agentes de control.

Tanto en América Latina y el Caribe como en Colombia se precisa un marco normativo más específico sobre el uso de AML para controlar la protesta pública. Asimismo, evaluar, entre otros factores, la posibilidad de que sean usadas por las Fuerzas Militares que deben prestar su servicio en estos casos, de tal forma que se respete el principio de proporcionalidad y se eviten situaciones de abuso de la fuerza y casos de fatalidad.

De acuerdo con la documentación de diferentes informes e investigaciones, la participación del Ejército Nacional en la contención de la protesta social se ha desarrollado especialmente en contextos de protesta en áreas rurales, especialmente en acciones desarrolladas por grupos campesinos, indígenas y afrodescendientes que se manifiestan en contra del desarrollo de proyectos mineros y de extracción de petróleo.

Finalmente, cabe señalar que Colombia no cuenta con datos estadísticos claros en materia de lesiones personales ni de muertes provocadas por las Fuerzas Militares y la Policía Nacional dentro del marco del control y la represión de la protesta social, situación que no permite dimensionar claramente la problemática respecto al abuso de la fuerza y el efecto del uso de armas letales por parte del Ejército Nacional.

\section{Declaración de divulgación}

Los puntos de vista y los resultados de este artículo pertenecen a los autores y no reflejan necesariamente los de la Escuela Militar de Cadetes “General José María Córdova”.

\section{Financiamiento}

Los autores no declaran fuente de financiamiento para la realización de este artículo.

\section{Sobre los autores}

Eder Julián Barbosa Parra. Capitán del Ejército Nacional de Colombia. Profesional en ciencias militares de la Escuela Militar de Cadetes "General José María Córdova” y Especialista en ciencias militares para el planeamiento de la Escuela de Armas Combinadas del Ejército Nacional. Contacto: eder.barbosa@buzonejercito.mil.co

\section{Referencias}

Amnistía Internacional. (s. f.). Uso de la fuerza: directrices para la aplicación de los principios básicos sobre el empleo de la fuerza y de armas de fuego por los funcionarios encargados de hacer cumplir la ley [información en página web]. Recuperado de https://www.ohchr.org/SP/ProfessionalInterest/Pages/UseOfForceAndFirearms.aspx

Arendt, H. (1970). Sobre la violencia. México: Joaquín Mortiz.

Betancourt, M. (2016). Minería, violencia y criminalización en América Latina. Santiago de Chile: Observatorio de Conflictos Mineros en América Latina. 
Casilimas, J. (2017). Manejo de la protesta social: entre la doctrina de la seguridad nacional y la propuesta de seguridad ciudadana. Bogotá, D. C.: Universidad Externado de Colombia.

Cobos, J. (2018). El pueblo Nasa del norte del Cauca: de la estigmatización de su protesta al exterminio de sus líderes [documento en línea]. Recuperado de http://www.indepaz.org.co/wp-content/ uploads/2018/09/Art\%C3\%ADculo-Ind\%C3\%ADgenas-Nasa-Cauca-ok.pdf

Cruz, E. (2015). El derecho a la protesta social en Colombia. Pensamiento Jurídico, (42), 47-69.

Gargarella, R. (2012). El derecho frente a la protesta social. Temas, 20, 22-29.

Godás, X. (2007). Política del disenso. Sociología de los movimientos sociales. Barcelona: Icarla.

Jiménez, W. \& Turizo, J. (2011). Militarización de la Policía y policización de las Fuerzas Militares. Revisión del fenómeno a nivel internacional y nacional. Revista Logos, Ciencia \& Tecnología, 3(1), 1-13.

Lalinde, S. (2019). Elogio a la bulla: protesta y democracia en Colombia. Bogotá, D. C.: Dejusticia.

Leal, F. (2002). La seguridad nacional a la deriva: del Frente Nacional a la Posguerra Fría. Bogotá, D. C.: Alfaomega.

Linz, J. (1993). La quiebra de las democracias. Madrid: Alianza.

Ministerio del Interior. (2018). Protocolo para la coordinación de las acciones de respeto y garantía a la protesta pacífica como un ejercicio legítimo de los derechos de reunión, manifestación pública y pacífica, libertad de asociación, libre circulación, a la libre expresión, libertad de conciencia, a la oposición y a la participación [documento en línea]. Recuperado de https://www.mininterior. gov.co/sites/default/files/180727-protocoloprotestapacifica.pdf

Moreno, J. (2014). Relaciones cívico-militares en Colombia: supremacía y control de los partidos políticos sobre la organización militar. Revista Científica General José María Córdova, 12(13), 333-352.

Movimiento Nacional de Víctimas de Crímenes de Estado [MOVICE] y Coordinación Colombia Europa Estados Unidos [CCEEU]. (2013).
Informe sobre protesta social y derechos humanos [documento en línea]. Recuperado de http://www.ddhhcolombia.org.co/sites/default/ files/files/pdf/CCEEU\%20Y\%20Movice_ Informe\%20ante\%20CIDH\%20SOBRE\%20 Criminalizacin\%20de\%20la\%20Protesta\%20 Social\%20en\%20Colombia.pdf

Observatorio de Conflictos Mineros en América Latina [OCMAL] y Centro Nacional Salud, Ambiente y Trabajo (CENSAT). (2016). Minería, violencia y criminalización en América Latina. Bogotá, D. C.: Observatorio de Conflictos Mineros en América Latina (OCMAL) y Centro Nacional Salud, Ambiente y Trabajo (CENSAT).

Organización de las Naciones Unidas [ONU]. (2016). Armas menos letales en América Latina y el Caribe: retos y oportunidades. Lima: Centro Regional de las Naciones Unidas para la Paz, el Desarme y el Desarrollo en América Latina y el Caribe.

Ortegón, J. (2016). ¡La tal marcha sí existe! Garantías para la protesta social en Colombia. Bogotá, D. C.: Pontificia Universidad Javeriana.

Passerin, A. (2001). La noción de Estado: una introducción a la teoría política. Barcelona: Ariel.

Policía Nacional de Colombia. (2008). Código de Policía.

Policía Nacional de Colombia. (2009). Criterios para el empleo de armas no letales [documento en página web]. Recuperado de http://finiterank. com/docs/63.pdf

Porta, D. D. (2011). Los movimientos sociales. Madrid: Complutense.

Tilly, C. \& Wood, E. (2010). Los movimientos sociales 1768-2008. Desde sus orígenes a Facebook. Barcelona: Crítica.

Toro, C., Corredor, C., Gutiérrez, D., Martínez, E. \& Grajales, J. (2017). Como el agua y el aceite. Conflictos socioambientales por la extracción petrolera. Bogotá, D. C.: CENSAT.

Touraine, A. (2006). Los movimientos sociales. Revista Colombiana de Sociología, (27), 255278.

Yarce, C. (2013). Militarización de la seguridad ciudadana en Medellín. Estudios de Derecho, 70(156), 268-290. 